\title{
Comparative Study of Moving Least Square and Point Interpolation Meshless Technique for Layered Composite Beam Subjected to Transverse Loading
}

\author{
Kunal Shah ${ }^{1}$, Appaso M. Gadade ${ }^{2 *}$ \\ ${ }^{1}$ Mechanical Engineering Department, Army Institute of Technology, Alandi Road, Pune 411015, India \\ ${ }^{2}$ Mechanical Engineering Department, Thapar Institute of Engineering and Technology, Patiala-147004, India \\ Corresponding Author Email: appaso.gadade@thapar.edu
}

https://doi.org/10.18280/mmep.070218

Received: 17 March 2020

Accepted: 23 May 2020

\section{Keywords:}

composite beam, meshless method, moving least square, point interpolation method, higher order beam theory, Timoshanko beam theory

\begin{abstract}
The present work proposes a computational procedure for evaluating the response of laminated composite beam subjected to transverse loading using moving least square and point interpolation meshless technique. A finite element procedure based on Higher-order Beam Theory (HBT) and Timoshanko Beam Theory (TBT) used for computing the deformation response of a laminated composite beam subjected to different loading conditions. The predictive capability of Moving Least Square (MLS) and Point Interpolation (PI) meshless technique is judged by comparing present results with the results of literature based on the exact solution technique. The deformation response of a laminated composite beam is obtained with several boundary conditions, aspect ratio, and lamination scheme. The exactness and soundness of the present computational algorithm are ensured by correlating results available with the results of various literature.
\end{abstract}

\section{INTRODUCTION}

The demand for the composite material is growing continuously in many significant applications of industries. This leads to the development of various modelling and analysis tools for the accurate prediction of response of composites subjected to different loading conditions. The computer-based numerical analysis helps in solving engineering problems which overcome time as well as challenges in solving partial differential equations. In the last decade, most of the researchers have shown interest in meshless methods for computing the stresses and deflections in laminated structures. The accuracy of deflection and stresses computation for the laminated composite and sandwich structures increases with the use of Higher-order theory over the First-order Shear Deformation Theory (FSDT) and classical theory [1-4]. The higher number of unknowns increases the complexity level of computation and demand for higher order theories with suitable assumptions [5]. The meshless methods combined with various analytical and numerical techniques are used for solving solid mechanics and fracture mechanics problems enables to include strong discontinuities such as cracks as well as weak discontinuities like material interfaces [6-8]. The element free Galerkin method is a substitution of finite element method which doesn't require element or nodal connectivity and there will not be a problem of any kind of locking and mainly used for solving static and dynamic crack problems [9-11]. This method is also useful for solving complex problems like sloshing of liquid in a composite container subjected to vibration excitation [12], vibration analysis of layered composite shell [13], layered composite plate with piezoelectric patches [14]. As elements are not used for meshing in the problem domain, meshless method permits to develop adaptive codes for structural response of solids and structures [15]. In recent past, moving least square mesh less approach is utilized for solving generalized KuramotoSivashinsky equation [16] and it is modified for scattered data approximation and smoothening [17]. The coupling of meshless method with peridynamics yields good results for 2D transient elastodynamic crack quandaries involving study of crack propagation [18]. The crack in the stiffened plates can be simulated by using meshless method via first order shear deformation theory and yields better results in comparison with the results obtained by using commercial software ANSYS [19]. A fluid structure interaction problem for aerodynamic damping of oscillating fan blade can be solved with mesh less method and results show an accuracy of $13 \%$ in comparison with experimental results [20]. A fractional reaction-subdiffusion equation can be solved by using spectral meshless radial point technique and results are in agreement with the results obtained by using analytical method [21]. A Graphics Processing Unit (GPU) based meshless methods can be used to simulate flows over two- and three-dimensional aerodynamic configurations by reordering multi layered points and significand enhancement in GPU speedups is achieved [22]. A robust method based on moving least squares meshless interpolation technique in conjunction with finite difference method for fluid flow simulation problems found more accurate and flexible [23]. A conjugate heat transfer problem for heat transfer devices can be simulated by using localized meshless technique [24]. The discontinuous Galerkin weak formulation with direct reconstruction surface integration method can be utilized for solving large scale Computational Fluid Dynamics (CFD) problems [25]. A two-dimensional linear elasticity [26] and fracture mechanics [27] problems can be solved by utilizing local mesh free numerical method with automatic optimization of discretization parameters. The 
acoustic field resulting from Helmholtz problems can be accurately represented by the plane wave basis functions with kemel meshfree approximation [28] and point interpolation shape functions [29].

The aim of the present study is to compare the response of laminated composite beam subjected to different loadings and obtained by MLS and PI meshless technique based on higherorder and Timoshenko beam theory. The deformation results are obtained for different aspect ratio, boundary conditions, and lamination angle. The results are compared with the similar results of various literature for ascertaining the accuracy of the present algorithm developed in MATLAB.

\section{MATHEMATICAL FORMULATION}

The laminated composite beam on a domain $\Omega$ of length $(l)$, width $(b)$ and overall thickness $(h)$ bounded by $\Gamma$ is considered for present study which occupies space as,

$$
0 \leq x \leq l ; \quad-\frac{b}{2} \leq y \leq \frac{b}{2} ; \quad-\frac{h}{2} \leq z \leq \frac{h}{2}
$$

The beam consists of $n$ number of laminas with different fiber orientation angle $(\beta)$ with positive $x$-axes. The displacements $(u, v, w)$ are considered along Cartesian coordinates $(x, y, z)$ as shown in Figure 1. The displacement $v$ is ideally assumed to be zero. Thus $(u, v, w)$ are functions of $x$ and $z$ represented as,

$$
\begin{aligned}
& u=u_{0}+z \theta_{x}+\alpha z^{3}\left(\theta_{x}+\frac{\partial w_{0}}{\partial x}\right) \\
& w=w_{0}
\end{aligned}
$$

where, $\alpha=0$ for TBT and $\alpha=-4 / 3 h^{2}$ for HBT. The field variables can be represented as axial displacement $\left(u_{0}\right)$, transverse displacement $\left(w_{0}\right)$, rotation about normal to the mid-surface $(\theta)$ and slope $(\partial w / \partial x)$. The strain displacement relation can be obtained as,

$$
\varepsilon=\left\{\begin{array}{c}
\varepsilon_{1}^{0}+z \varepsilon_{1}^{1}+z^{3} \varepsilon_{1}^{3} \\
\varepsilon_{5}^{0}+z^{2} \varepsilon_{5}^{2}
\end{array}\right\}=\left[\begin{array}{ccccc}
1 & z & z^{3} & 0 & 0 \\
0 & 0 & 0 & 1 & z^{2}
\end{array}\right]\left\{\begin{array}{c}
\varepsilon_{1}^{0} \\
\varepsilon_{1}^{1} \\
\varepsilon_{1}^{3} \\
\varepsilon_{5}^{0} \\
\varepsilon_{5}^{2}
\end{array}\right\}
$$

where,

$$
\left\{\begin{array}{c}
\varepsilon_{1}^{0} \\
\varepsilon_{1}^{1} \\
\varepsilon_{1}^{3} \\
\varepsilon_{5}^{0} \\
\varepsilon_{5}^{2}
\end{array}\right\}=\left\{\begin{array}{c}
\frac{\partial u_{0}}{\partial x} \\
\frac{\partial \theta_{x}}{\partial x} \\
\alpha\left(\frac{\partial \theta_{x}}{\partial x}+\frac{\partial^{2} w_{0}}{\partial x^{2}}\right) \\
\theta_{x}+\frac{\partial w_{0}}{\partial x} \\
3 \alpha\left(\theta_{x}+\frac{\partial w_{0}}{\partial x}\right)
\end{array}\right\}=[L]\{\tilde{U}\}
$$

with differential operator,

$$
[L]=\left[\begin{array}{cccc}
\frac{\partial}{\partial x} & 0 & 0 & 0 \\
0 & 0 & \frac{\partial}{\partial x} & 0 \\
0 & 0 & \alpha \frac{\partial}{\partial x} & \alpha \frac{\partial}{\partial x} \\
0 & \frac{\partial}{\partial x} & 1 & 0 \\
0 & 0 & 3 \alpha & 3 \alpha
\end{array}\right]
$$

and displacement vector,

$$
\{\tilde{U}\}=\left\{\begin{array}{llll}
u & w & \theta & \frac{\partial w}{\partial x}
\end{array}\right\}
$$

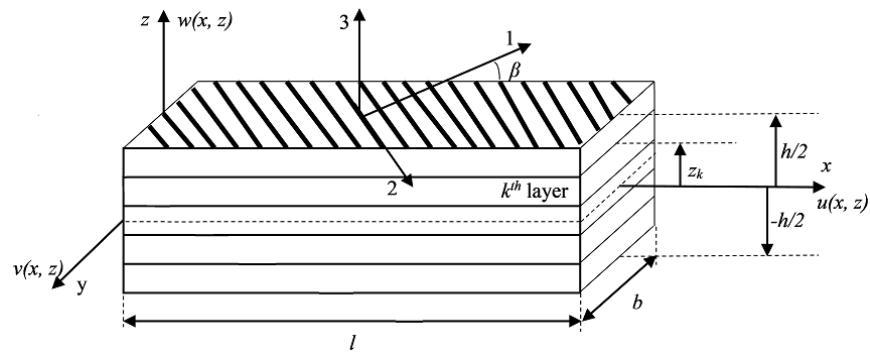

Figure 1. Laminated composite beam with local and global coordinate system

\section{MESHLESS METHOD}

The static problem in solid mechanics can be solved with the help of equilibrium equation given by,

$$
L^{T} \sigma=0 \text { in } \quad \Omega
$$

where, stress vector $\sigma$ can be represented with stress resultants $N, M, P, Q, R$ as,

$$
\left\{\begin{array}{l}
N \\
M \\
P \\
Q \\
R
\end{array}\right\}=\left[\begin{array}{ccccc}
A_{1} & B_{1} & E_{1} & 0 & 0 \\
B_{1} & D_{1} & F_{1} & 0 & 0 \\
E_{1} & F_{1} & H_{1} & 0 & 0 \\
0 & 0 & 0 & A_{5} & D_{5} \\
0 & 0 & 0 & D_{5} & F_{5}
\end{array}\right]\left\{\begin{array}{c}
\varepsilon_{1}^{0} \\
\varepsilon_{1}^{1} \\
\varepsilon_{1}^{3} \\
\varepsilon_{5}^{0} \\
\varepsilon_{5}^{2}
\end{array}\right\}
$$

and resultant material stiffness constants as,

$$
\begin{aligned}
& \left(A_{1}, B_{1}, D_{1}, E_{1}, F_{1}, H_{1}\right)=b \int_{-h / 2}^{h / 2} \hat{C}_{11}\left(1, z, z^{2}, z^{3}, z^{4}, z^{6}\right) d z ; \\
& \left(A_{5}, D_{5}, F_{5}\right)=b \int_{-h / 2}^{h / 2} \hat{C}_{13}\left(1, z^{2}\right) d z
\end{aligned}
$$

where,

$$
\begin{aligned}
& \hat{C}_{11}=\bar{C}_{11}+\bar{C}_{12} \frac{\bar{C}_{16} \bar{C}_{26}-\bar{C}_{12} \bar{C}_{66}}{\bar{C}_{22} \bar{C}_{66}-\bar{C}_{26} \bar{C}_{26}}+\bar{C}_{16} \frac{\bar{C}_{12} \bar{C}_{26}-\bar{C}_{16} \bar{C}_{22}}{\bar{C}_{22} \bar{C}_{66}-\bar{C}_{26} \bar{C}_{26}} \\
& \hat{C}_{13}=\bar{C}_{45} \frac{\bar{C}_{45}}{\bar{C}_{44}}+\bar{C}_{55}
\end{aligned}
$$

and transformed stiffness constants, $\bar{C}_{i j}$ are described by 
Reddy [30].

The natural boundary conditions are applied as,

$$
\sigma n=\bar{t} \quad \text { in } \quad \Gamma_{t}
$$

where, $\bar{t}$ is traction force at the natural boundaries and $n$ is unit normal vector on the natural boundary. The constraints can be applied with the help of essential boundary condition as,

$$
U=\bar{U} \quad \text { in } \quad \Gamma_{u}
$$

The displacement at the essential boundaries are $\bar{U}$.

\subsection{Element Free Galerkin method}

The MLS is an approximation procedure utilized for shape function generation in Element Free Galerkin (EFG) technique. The shape functions are generated utilizing the cubic spline weighted function as explained by Belytschko [6]. The shape functions $\phi$ formed by the assistance of nodes in local support domain as,

$$
U_{4 \times 1}=\Phi_{4 n \times 4 n} U_{4 n \times 1}
$$

The MLS approximations does not possess Kronecker delta property due to which constrained weak form of onedimensional beam is required and can be represented as [6],

$$
\begin{aligned}
& \int_{\Omega}(L \delta u)^{T} D_{e q}(L u) d \Omega-\int_{\Gamma_{t}} \delta u^{T} \bar{t} d \Gamma-\int_{\Gamma_{u}} \delta \lambda^{T}(u-\bar{u}) d \Gamma- \\
& \int_{\Gamma_{u}} \delta u^{T} \lambda d \Gamma=0
\end{aligned}
$$

where, Lagrange multipliers $\lambda$ in Eq. (14), are used to maintain compatibility. These unknown functions of the coordinates are interpolated at nodes on essential boundaries using their shape functions and nodal values.

$$
\lambda=\sum_{i=1}^{n} N_{I} \lambda_{I}
$$

where, $N_{I}$ is the matrix of shape functions for $i^{\text {th }}$ node on the essential boundary. In Eq. (15), the shape function $N_{I}(s)$ are the Lagrange interpolants of first order. In a simple case, the essential boundaries are discretized using line segments. The Lagrange multiplier is interpolated using two nodes at the two ends of this line segments. The variation of the Lagrange multiplier given by,

$$
\delta \lambda^{h}=N \delta \lambda
$$

The weak form of Eq. (14) can be obtained by replacing the trial functions, test functions as,

$$
\left[\begin{array}{cc}
K & G \\
G^{T} & 0
\end{array}\right]_{(4 n+4 n \lambda t) \times(4 n+4 n \lambda t)}\left\{\begin{array}{l}
U \\
\Lambda
\end{array}\right\}_{(4 n+4 n \lambda t) \times 1}=\left\{\begin{array}{l}
F \\
Q
\end{array}\right\}_{(4 n+4 n \lambda t) \times 1}
$$

where,

$$
\begin{gathered}
K_{4 n \times 4 n}=[B]_{4 n \times 5}^{T}[D]_{5 \times 5}[B]_{5 \times 4 n} \\
G_{4 n \times 4 n \lambda t}=N_{4 n \times 4 n \lambda t} \Phi \\
F_{(4 n \times 1)}=\int_{\Omega} \Phi_{(4 n \times 1)} \bar{t} d \Gamma \\
q_{4 n \lambda t \times 1}=\int_{T_{c}} N_{4 n \lambda t \times 4 n \lambda t} \bar{u}_{4 n \lambda t \times 1} d \Gamma
\end{gathered}
$$

where,

$$
B_{5 \times 4 n}=[L]_{5 \times 4}[\Phi]_{4 \times 4 n}
$$

\subsection{Point interpolation method}

The PI method is another meshless technique developed by Liu [15]. The PI method possess Kronecker delta property, which eliminates requirement of Lagrangian multipliers in EFG method. The final discrete equations can be obtained similar to finite element method, by eliminating $G$ and $q$ terms in Eq. (17) as [15]

$$
[K]_{(4 n \times 4 n)}\{U\}_{(4 n \times 1)}=\{F\}_{(4 n \times 1)}
$$

where, $K$ and $F$ can be obtained by replacing PI method shape functions in place of MLS shape functions. The essential boundary conditions can be handled by direct method. The components in the global force vector are modified to,

$$
F_{i j} \Rightarrow \begin{cases}\bar{u}_{i} & i=j \\ F_{j}-K_{j i} u_{i} & i \neq j\end{cases}
$$

\section{RESULTS AND DISCUSSION}

The present algorithm for $H B T$ and $T B T$ developed in MATLAB is validated for ensuring its accuracy by comparing deformation with the $M L S$ and $P I$ approximation method. The results are compared with Murthy [3] and Khdier [2] for asymmetric cross-ply beam [0/90] as well as symmetric crossply beam $[0 / 90 / 0]_{s}$ as shown in Table 1 and Table 2, respectively. The transverse deflection of a laminated composite beam under UDL for clamped-clamped $(C-C)$, hinged-hinged $(H-H)$, clamped-hinged $(C-H)$ and clamp-free $(C-F)$ boundary conditions are obtained. The convergence study is carried out, and finally, the laminated beam is discretized using 101 number of nodes. The material properties used are $E_{1}=E_{2} / 25, G_{12}=G_{13}=0.5 E_{2}, G_{23}=0.2 E_{2}$, and $v_{12}=0.25$. The non-dimensional form of transverse deflection of laminated composite beam is given by,

$$
\bar{w}=\frac{100 E_{2} h^{3}}{q L^{4}} w_{(l / 2)}
$$

From Tables 1 and 2, it is observed that HBT shows better results than Timoshenko theory for various boundary conditions. The accuracy of computation increases with the increase in aspect ratio $(L / h)$. Both MLS and PI method 
approximation techniques shows good agreement with the similar results of previous literature. It is also observed that the results obtained with the PI method are more promising than MLS. The variation of $10 \%$ is observed when the aspect ratio is small, and error reduces with the increase in aspect ratio.

Table 1. Non-dimensional deflection $(\bar{w}(0, L / 2))$ of asymmetric cross-ply [0/90] beam for different boundary conditions with uniformly distributed load

\begin{tabular}{cccccc}
\hline$L / h$ & Model & $H-H$ & $C-H$ & $C-C$ & $C-F$ \\
\hline 5 & Present HBT-PIM & 4.833 & 2.766 & 2.150 & 15.783 \\
& Present TBT-PIM & 5.379 & 3.317 & 2.722 & 17.465 \\
& Present HBT-MLS & 4.839 & 2.789 & 2.178 & 15.808 \\
& Present TBT-MLS & 5.396 & 3.339 & 2.756 & 17.477 \\
& Murthy [3] & 4.750 & 2.855 & 1.924 & 15.334 \\
& Khdeir [2] & 4.777 & 2.863 & 1.922 & 15.279 \\
\hline 10 & Present HBT-PIM & 3.701 & 1.545 & 1.039 & 12.424 \\
& Present TBT-PIM & 3.836 & 1.682 & 1.179 & 12.837 \\
& Present HBT-MLS & 3.690 & 1.570 & 1.054 & 12.462 \\
& Present TBT-MLS & 3.832 & 1.705 & 1.194 & 12.876 \\
& Murthy [3] & 3.668 & 1.736 & 1.007 & 12.398 \\
& Khdeir [2] & 3.688 & 1.740 & 1.005 & 12.343 \\
\hline 50 & Present HBT- PIM & 3.337 & 1.143 & 0.679 & 11.3389 \\
& Present TBT-PIM & 3.342 & 1.147 & 0.685 & 11.355 \\
& Present HBT-MLS & 3.219 & 1.141 & 0.667 & 11.056 \\
& Present TBT-MLS & 3.260 & 1.156 & 0.679 & 11.175 \\
& Murthy [3] & 3.318 & 1.343 & 0.681 & 11.392 \\
& Khdeir [2] & 3.336 & 0.679 & 0.679 & 11.337 \\
\hline
\end{tabular}

Table 2. Non-dimensional deflection $(\bar{w}(0, L / 2))$ of asymmetric cross-ply [0/90/0] beam for different boundary conditions with uniformly distributed load

\begin{tabular}{cccccc}
\hline$L / h$ & Model & $H-H$ & $C-H$ & $C-C$ & $C-F$ \\
\hline 5 & Present HBT-PIM & 2.426 & 2.062 & 1.688 & 7.161 \\
& Present TBT-PIM & 2.446 & 2.239 & 1.929 & 7.598 \\
& Present HBT-MLS & 2.438 & 2.073 & 1.708 & 7.146 \\
& Present TBT-MLS & 2.467 & 2.247 & 1.952 & 7.569 \\
& Murthy [3] & 2.398 & 1.946 & 1.538 & 6.836 \\
& Khdeir [2] & 2.412 & 1.952 & 1.537 & 6.824 \\
\hline 10 & Present HBT-PIM & 1.105 & 0.761 & 0.555 & 3.512 \\
& Present TBT-PIM & 1.096 & 0.778 & 0.579 & 3.548 \\
& Present HBT-MLS & 1.107 & 0.767 & 0.561 & 3.516 \\
& Present TBT-MLS & 1.100 & 0.782 & 0.587 & 3.549 \\
& Murthy [3] & 1.090 & 0.738 & 0.532 & 3.466 \\
& Khdeir [2] & 1.096 & 0.740 & 0.532 & 3.455 \\
\hline 50 & Present HBT- PIM & 0.665 & 0.280 & 0.148 & 2.253 \\
& Present TBT-PIM & 0.664 & 0.279 & 0.147 & 2.252 \\
& Present HBT-MLS & 0.658 & 0.288 & 0.149 & 2.249 \\
& Present TBT-MLS & 0.660 & 0.289 & 0.149 & 2.253 \\
& Murthy [3] & 0.661 & 0.279 & 0.147 & 2.262 \\
& Khdeir [2] & 0.665 & 0.280 & 0.147 & 2.251 \\
\hline
\end{tabular}

Figure 2 shows transverse deflection of a laminated composite beam subjected to UDL for various boundary conditions and different (a) lamination angle at aspect ratio $(L / h=10)$ with $\left[\theta_{4} / 0_{4} / \theta_{4}\right]$ lamination scheme, $(b)$ aspect ratio $(L / h)$ with lamination scheme $[0 / 90]_{\text {s. It }}$ is observed from the results that the clamped-free boundary condition shows more deformation for all lamination angles, as shown in Figure 2(a). It is also observed from Figure 2( $a$ ) that deformation increases with the lamination angle. It is observed from Figure $2(b)$ that the deformation results are more consistent for higher aspect ratio.
Table 3 and Table 4 show effect of lamination schemes and plate thickness on non-dimensional transverse deflection of a laminated composite beam under uniformly distributed load and Point load for Clamped-Clamped $(C C)$ boundary conditions respectively. The response of beam is obtained for unidirectional ply, cross ply and angle ply lamination schemes. The lamination schemes considered are [0], [90], [0/90], $[0 / 90]_{\mathrm{s}},[0 / 90 / 0]_{\mathrm{s}}$ and $[45 /-45]_{\mathrm{s}}$. The plate aspect ratio considered for this study are 5, 10, 20, 50 and 100. The results are obtained using point interpolation and moving least square mesh less technique via higher order beam theory and Timoshenko beam theory for different aspect ratios $(L / h)$. For all the cases considered it is observed that the response of laminated composite beam in the form of deformation is higher for transverse loading condition. This clearly indicates that laminated composite beam has lower strength if the load is applied transverse to fibre direction and it is strong if the load is applied along the fibre.

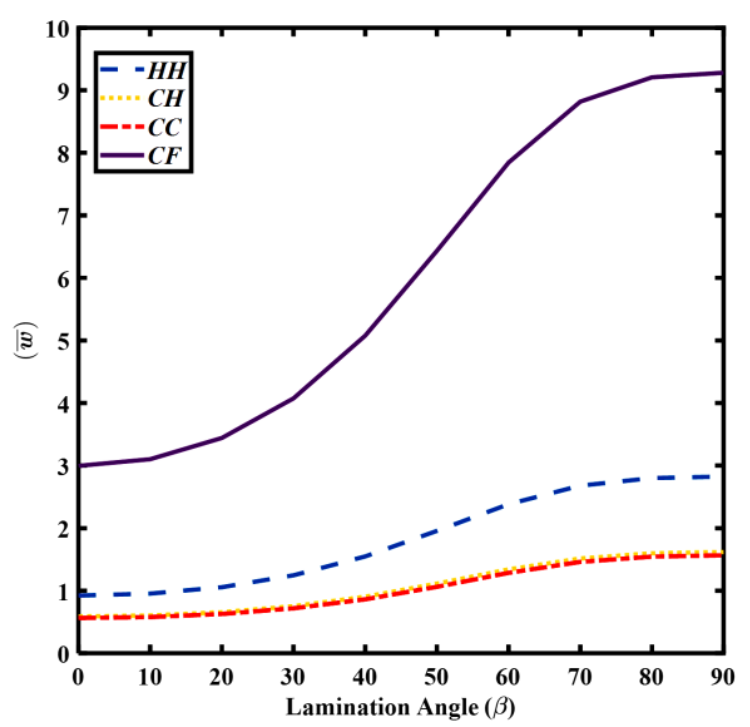

(a)

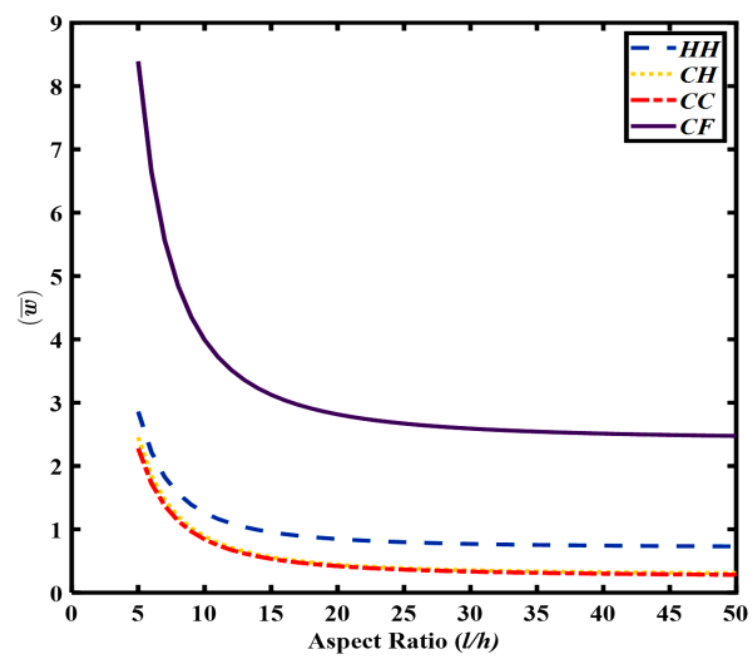

(b)

Figure 2. Transverse deformation response of laminated beam subjected to different boundary conditions with respect to $(a)$ lamination scheme $(\beta 4 / 04 / \beta 4)_{\mathrm{s}}$ at aspect ratio 10 and (b) aspect ratio for lamination scheme $(0 / 90)_{\mathrm{s}}$ 
Table 3. Effect of lamination scheme and plate thickness on non-dimensional transverse deflection of laminated beam under UDL for Clamped-Clamped boundary conditions

\begin{tabular}{|c|c|c|c|c|c|}
\hline$L / h$ & $\begin{array}{c}\text { Lamination } \\
\text { scheme }\end{array}$ & $\begin{array}{c}\mathrm{HBT} \\
(\mathrm{PI})\end{array}$ & $\begin{array}{c}\text { HBT } \\
(\mathrm{MLS})\end{array}$ & $\begin{array}{l}\text { TBT } \\
\text { (PI) }\end{array}$ & $\begin{array}{c}\text { TBT } \\
(\mathrm{MLS})\end{array}$ \\
\hline \multirow[t]{6}{*}{5} & [0] & 1.2317 & 1.2463 & 1.5644 & 1.5835 \\
\hline & [90] & 6.0406 & 6.1141 & 6.7127 & 6.8071 \\
\hline & [0/90] & 2.1503 & 2.1771 & 2.7204 & 2.7560 \\
\hline & {$[0 / 90]_{\mathrm{s}}$} & 2.0219 & 2.0446 & 2.1984 & 2.2251 \\
\hline & {$[0 / 90 / 0]_{\mathrm{s}}$} & 1.6655 & 1.6847 & 2.0501 & 2.0751 \\
\hline & {$[45 /-45]_{\mathrm{s}}$} & 2.0646 & 2.0875 & 2.4924 & 2.5257 \\
\hline \multirow[t]{6}{*}{10} & [0] & 0.4127 & 0.4176 & 0.4845 & 0.4909 \\
\hline & [90] & 3.8570 & 3.8979 & 4.0130 & 4.0690 \\
\hline & [0/90] & 1.0397 & 1.0528 & 1.1777 & 1.1946 \\
\hline & {$[0 / 90]_{\mathrm{s}}$} & 0.6544 & 0.6612 & 0.6557 & 0.6642 \\
\hline & {$[0 / 90 / 0]_{\mathrm{s}}$} & 0.5458 & 0.5521 & 0.6292 & 0.6375 \\
\hline & {$[45 /-45]_{\mathrm{s}}$} & 0.8551 & 0.8640 & 0.9497 & 0.9646 \\
\hline \multirow[t]{6}{*}{20} & [0] & 0.1982 & 0.2006 & 0.2145 & 0.2176 \\
\hline & [90] & 3.3028 & 3.3094 & 3.3381 & 3.3610 \\
\hline & [0/90] & 0.7587 & 0.7656 & 0.7920 & 0.8023 \\
\hline & {$[0 / 90]_{\mathrm{s}}$} & 0.2754 & 0.2783 & 0.2701 & 0.2739 \\
\hline & {$[0 / 90 / 0]_{\mathrm{s}}$} & 0.2549 & 0.2579 & 0.2740 & 0.2779 \\
\hline & {$[45 /-45]_{\mathrm{s}}$} & 0.5433 & 0.5475 & 0.5641 & 0.5735 \\
\hline \multirow[t]{6}{*}{50} & [0] & 0.1366 & 0.1373 & 0.1389 & 0.1404 \\
\hline & [90] & 3.1465 & 2.9174 & 3.1491 & 3.0058 \\
\hline & [0/90] & 0.6795 & 0.6661 & 0.6840 & 0.6793 \\
\hline & {$[0 / 90]_{\mathrm{s}}$} & 0.1636 & 0.1646 & 0.1621 & 0.1640 \\
\hline & {$[0 / 90 / 0]_{\mathrm{s}}$} & 0.1718 & 0.1728 & 0.1745 & 0.1765 \\
\hline & {$[45 /-45]_{\mathrm{s}}$} & 0.4545 & 0.4494 & 0.4561 & 0.4582 \\
\hline \multirow[t]{6}{*}{100} & [0] & 0.1276 & 0.1248 & 0.1281 & 0.1270 \\
\hline & [90] & 3.1240 & 2.3106 & 3.1221 & 2.5190 \\
\hline & {$[0 / 90]$} & 0.6681 & 0.5943 & 0.6686 & 0.6193 \\
\hline & {$[0 / 90]_{\mathrm{s}}$} & 0.1472 & 0.145 & 0.1466 & 0.1462 \\
\hline & {$[0 / 90 / 0]_{\mathrm{s}}$} & 0.1598 & 0.1565 & 1.6030 & 0.1592 \\
\hline & {$[45 /-45]_{\mathrm{s}}$} & 0.4418 & 0.4089 & 0.4407 & 0.4225 \\
\hline
\end{tabular}

Table 4. Effect of lamination scheme and plate thickness on non-dimensional transverse deflection of laminated beam under point load for Clamped-Clamped boundary conditions

\begin{tabular}{cccccc}
\hline$L / h$ & $\begin{array}{c}\text { Lamination } \\
\text { scheme }\end{array}$ & $\begin{array}{c}\text { HBT } \\
(\mathrm{PI})\end{array}$ & $\begin{array}{c}\text { HBT } \\
(\mathrm{MLS})\end{array}$ & $\begin{array}{c}\text { TBT } \\
(\mathrm{PI})\end{array}$ & $\begin{array}{c}\text { TBT } \\
(\mathrm{MLS})\end{array}$ \\
\hline 5 & {$[0]$} & 2.457 & 2.439 & 2.641 & 2.621 \\
& {$[90]$} & 12.066 & 11.992 & 12.214 & 12.128 \\
& {$[0 / 90]$} & 4.291 & 4.261 & 4.746 & 4.711 \\
& {$[0 / 90]_{\mathrm{s}}$} & 4.034 & 4.007 & 3.700 & 3.672 \\
& {$[0 / 90 / 0]_{\mathrm{s}}$} & 3.322 & 3.299 & 3.459 & 3.432 \\
& {$[45 /-45]_{\mathrm{s}}$} & 4.120 & 4.091 & 4.292 & 4.260 \\
\hline 10 & {$[0]$} & 0.824 & 0.818 & 0.847 & 0.841 \\
& {$[90]$} & 7.711 & 7.671 & 7.729 & 7.676 \\
& {$[0 / 90]$} & 2.077 & 2.062 & 2.183 & 2.168 \\
& {$[0 / 90]_{\mathrm{s}}$} & 1.306 & 1.298 & 1.138 & 1.130 \\
& {$[0 / 90 / 0]_{\mathrm{s}}$} & 1.090 & 1.081 & 1.098 & 1.090 \\
& {$[45 /-45]_{\mathrm{s}}$} & 1.708 & 1.697 & 1.729 & 1.717 \\
\hline 20 & {$[0]$} & 0.396 & 0.393 & 0.399 & 0.396 \\
& {$[90]$} & 6.606 & 6.562 & 6.608 & 6.565 \\
& {$[0 / 90]$} & 1.517 & 1.502 & 1.542 & 1.532 \\
& {$[0 / 90]_{\mathrm{s}}$} & 0.550 & 0.547 & 0.497 & 0.494 \\
& {$[0 / 90 / 0]_{\mathrm{s}}$} & 0.509 & 0.509 & 0.508 & 0.505 \\
& {$[45 /-45]_{\mathrm{s}}$} & 1.086 & 1.080 & 1.089 & 1.080 \\
\hline 50 & {$[0]$} & 0.273 & 0.271 & 0.273 & 0.272 \\
& {$[90]$} & 6.294 & 6.247 & 6.294 & 6.248 \\
& {$[0 / 90]$} & 1.359 & 1.350 & 1.363 & 1.353 \\
& {$[0 / 90]_{\mathrm{s}}$} & 0.327 & 0.325 & 0.318 & 0.316 \\
& {$[0 / 90 / 0]_{\mathrm{s}}$} & 0.344 & 0.341 & 0.343 & 0.341 \\
& {$[45 /-45]_{\mathrm{s}}$} & 0.909 & 0.903 & 0.909 & 0.903 \\
\hline 100 & {$[0]$} & 0.255 & 0.254 & 0.255 & 0.254 \\
& {$[90]$} & 6.248 & 6.179 & 6.249 & 6.184 \\
& {$[0 / 90]$} & 1.336 & 1.325 & 1.337 & 1.327 \\
& & & & &
\end{tabular}

$\begin{array}{ccccc}{[0 / 90]_{\mathrm{s}}} & 0.294 & 0.292 & 0.292 & 0.290 \\ {[0 / 90 / 0]_{\mathrm{s}}} & 0.320 & 0.317 & 0.319 & 0.318 \\ {[45 /-45]_{\mathrm{s}}} & 0.884 & 0.877 & 0.884 & 0.877\end{array}$

\section{CONCLUSIONS}

The static bending response of a laminated composite beam subjected to transverse loading is obtained by implementing MLS and PI meshless method based on HBT and TBT. A MATLAB code is developed and validated for its accuracy by comparing deformation results with various literature. The effects of aspect ratio $(L / h)$, different boundary conditions, symmetric, and asymmetric laminates for linearly static bending are examined.

It is concluded from the results obtained under different loading and boundary conditions that the TBT can be used where computational cost is priority, while the HBT can be used where accuracy is priority.

The variation of results by utilizing MLS and PI method is not considerable for same nodal density. The PI method possesses Kroneckere delta property, which simplifies implementation of essential boundary conditions. Also, the results get converged quickly and hence can be better choice than the EFG with MLS method.

\section{REFERENCES}

[1] Reddy, J.N. (1984). A simple higher order theory for laminated composite plates. Journal of Applied Mechanics, 51(4): 745-752. https://doi.org/10.1115/1.3167719

[2] Khdeir, A.A. (1997). An exact solution for the bending of thin and thick cross-ply laminated beams. Composite Structures, 37(2): 195-203. https://doi.org/10.1016/S0263-8223(97)80012-8

[3] Murthy, M. V.V.S., Roy, M., Badarinarayana, D.K., Gopalakrishnan, S. (2005). A refined higher order finite element for asymmetric composite beams. Composite Structures, 67(1): 27-35. https://doi.org/10.1016/j.compstruct.2004.01.005

[4] Ferreira, A.J.M., Roque, C.M.C., Martins, P.A.L.S. (2004). Radial basis functions and higher-order shear deformation theories in the analysis of laminated composite beams and plate. Composite Structures, 66(14): 287-293. https://doi.org/10.1016/j.compstruct.2004.04.050

[5] Abrate, S., Sciuva, M.D. (2017). Equivalent single layer theories for composite and sandwich structures: A review. Composite Structures, 179: 482-494. https://doi.org/10.1016/j.compstruct.2017.07.090

[6] Belytschko, T., Krongauz, Y., Organ, D., Fleming, M., Krys1, P. (1996). Meshless methods: An overview and recent developments. Computer Methods in Applied Mechanics and Engineering, 139(1-4): 3-47. https://doi.org/10.1016/S0045-7825(96)01078-X

[7] Nguyen, V. P., Rabczuk, T., Bordas, S., Duflot, M. (2008). Meshless methods: A review and computer implementation aspects. Mathematics and Computers in Simulation, 79(3): 763-813. https://doi.org/10.1016/j.matcom.2008.01.003

[8] Wen, P.H., Yang, J.J., Huang, T., Zheng, J.L., Deng, Y.J. (2018). Infinite element in meshless approaches. 
European Journal of Mechanics - A/Solids, 72: 175-185. https://doi.org/10.1016/j.euromechsol.2018.05.010

[9] Belytschko, T., Lu, Y.Y., Gu, L. (1994). Element free Galerkin methods. International Journal of Numerical Methods in Engineering, 37(2): 229-256. https://doi.org/10.1002/nme.1620370205

[10] Belytschko, T., Lu, Y.Y., Gu, L., Tabbara, M. (1995). Element-free galerkin methods for static and dynamic fracture. International Journal of Solids and Structures, 32(17-18): 2547-2570. https://doi.org/10.1016/00207683(94)00282-2

[11] Ren, H., Cheng, Y. (2012). The interpolating elementfree Galerkin (IEFG) method for two-dimensional potential problems. Engineering Analysis with Boundary Elements, $\quad 36(5)$ : 873-880. https://doi.org/10.1016/j.enganabound.2011.09.014

[12] Pal, P., Bhattacharyya, S.K. (2013). Slosh dynamics of liquid-filled composite containers-A two dimensional meshless local Petrov-Galerkin approach. Journal of Fluids and Structures, 39: 60-75. https://doi.org/10.1016/j.jfluidstructs.2013.02.002

[13] Zhao, X., Liew, K.M., Ng, T.Y. (2003). Vibration analysis of laminated composite cylindrical panels via a meshfree approach. International Journal of Solids and Structures, 40(1): $161-$ 180.https://doi.org/10.1016/S0020-7683(02)00475-4

[14] Liew, K.M., He, X.Q., Tan, M.J., Lima, H.K. (2004). Dynamic analysis of laminated composite plates with piezoelectric sensor/actuator patches using the FSDT mesh-free method. International Journal of Mechanical Sciences, $46(3)$ : 411-431. https://doi.org/10.1016/j.ijmecsci.2004.03.011

[15] Liu, G.R., Gu, Y.T. (2001). A point interpolation method for two-dimensional solids. International Journal of Numerical Methods Engineering, 50(4): 937-951. https://doi.org/10.1002/10970207(20010210)50:4<937::AID-NME62>3.0.CO;2-X

[16] Dabboura, E., Sadat, H., Prax, C. (2016). A moving least squares meshless method for solving the generalized Kuramoto-Sivashinsky equation. Alexandria Engineering Journal, 55(3): 2783-2787. https://doi.org/10.1016/j.aej.2016.07.024

[17] Joldes, G.R., Chowdhury, H.A., Wittek, A., Doyle, B., Miller, K. (2015). Modified moving least squares with polynomial bases for scattered data approximation. Applied Mathematics and Computation, 266(1): 893902. https://doi.org/10.1016/j.amc.2015.05.150

[18] Shojaei, A., Mudric, T., Zaccariotto, M., Galvanetto, U. (2016). A coupled meshless finite point/Peridynamic method for $2 \mathrm{D}$ dynamic fracture analysis. International Journal of Mechanical Sciences, 119: 419-431. https://doi.org/10.1016/j.ijmecsci.2016.11.003

[19] Peng, L.X., Tao, Y., Liang, N., Li, L., Qin, X., Zeng, Z., Teng, X. (2017). Simulation of a crack in stiffened plates via a meshless formulation and FSDT. International
Journal of Mechanical Sciences, 131-132: 880-893. https://doi.org/10.1016/j.ijmecsci.2017.07.063

[20] Peters, C.D., Spuy, S.J., Daniel, N.J., Kuhnert, J. (2018). Aerodynamic damping of an oscillating fan blade: Meshbased and meshless fluid structure interaction analysis. Journal of Fluids and Structures, 82: 173-197. https://doi.org/10.1016/j.jfluidstructs.2018.07.010

[21] Shivanian, E., Jafarabadi, A. (2018). Analysis of the spectral meshless radial point interpolation for solving fractional reaction-sub diffusion equation. Journal of Computational and Applied Mathematics, 336: 98-213. https://doi.org/10.1016/j.cam.2017.11.046

[22] Cao, C., Chen, H., Zhang, J., Xu, S. (2019). A multilayered point reordering study of GPU-based meshless method for compressible flow simulations. Journal of Computational Science, 33: 45-60. https://doi.org/10.1016/j.jocs.2019.04.001

[23] Sousa, F.S., Lages, C.F., Ansoni, J.L., Castelo, A., Simao, A. (2019). A finite difference method with meshless interpolation for incompressible flows in non-graded tree-based grids. Journal of Computational Physics, 396: 848-866. https://doi.org/10.1016/j.jcp.2019.07.011

[24] Wijayanta, A.T., Pranowo. (2020). A localized meshless approach using radial basis functions for conjugate heat transfer problems in a heat exchanger. International Journal of Refrigeration, 110: 38-46. https://doi.org/10.1016/j.ijrefrig.2019.10.025

[25] You, H., Kim, C. (2020). Direct reconstruction method for discontinuous Galerkin methods on higher-order mixed-curved meshes II. Surface integration. Journal of Computational Physics, 416: 109514. https://doi.org/10.1016/j.jcp.2020.109514

[26] Santana, E., Oliveira, T., Vélez, W., Araújo, A., Martins, F., Portela, A. (2020). A local mesh free numerical method with automatic parameter optimization. Engineering Analysis with Boundary Elements, 113: 5571. https://doi.org/10.1016/j.enganabound.2019.12.013

[27] Oliveira, T., Vélez, W., Santana, E., Araújo, T., Mendonça, F., Portela, A. (2019). A local mesh free method for linear elasticity and fracture mechanics. Engineering Analysis with Boundary Elements, 101: 221-242.

https://doi.org/10.1016/j.enganabound.2019.01.007

[28] Wang, J., Wu, J., Wang, D. (2020). A quasi-consistent integration method for efficient meshfree analysis of Helmholtz problems with plane wave basis functions. Engineering Analysis with Boundary Elements, 110: 4255. https://doi.org/10.1016/j.enganabound.2019.10.002

[29] You, X., Chai, Y., Li, W. (2019). A coupled FE-meshfree method for Helmholtz problems using point interpolation shape functions and edge-based gradient smoothing technique. Computers \& Structures, 213: 1-22. https://doi.org/10.1016/j.compstruc.2018.07.011

[30] Reddy, J.N. (2004). Mechanics of Laminated Composite Plates and Shells. CRC Press LLC. 